$184 s$

\title{
Abuse/craving: \\ - treatment
}

EXPERIMENTAL AND CLINICAL RESULTS OF DRUG AND ALCOHOL ADDICTION TREATMENT WITH CHOLECYSTOKININ (CCK)

\section{P. Anokhina}

Institute on Medicobiological Problems of Addiction, Malyi Mogiltsevsky per. 3, 121921 Moscow, Russia

A neuropeptide, CCK-8, administered to rats with alcohol and opiate dependence decreases voluntary alcohol and drug consumption. CCK-8 also arrests rapidly behavioral, vegetative and biochemical symptoms of experimental alcohol and opiate withdrawal syndromes. Intravenous injection of CCK-32 to patients with heavy alcohol and oplate withdrawal syndromes causes fast disappearance of psychovegetative disturbances, reduces pathological craving for alcohol and drugs and normalizes the level and metabolism of dopamine in the blood. It is concluded that CCK or its analogues could be used for the treatment of alcohol and opiate addiction.
DISULFIRAM ADMINISTERED BY A TRUSTEE IMPROVES QUALITY OF LIFE (QOL) IN ALCOHOLIC OUTPATIENTS M Gerber, CRB Joyce, A Christen, U Dudle, I Duss, P Widler, HU FISCH Departments of Psychiatry, Clinical Pharmacology, University of Bem, 3010 Bern, and Migros-Genossenschaft, 3321 Schoenbuehl, Switzerland

Alcoholism has a major impact on aspects of life relevant to individual QoL. Perceived increase of QoL during treatment may encourage the patient to further abstinence, but the effect of treatment on QoL in alcoholism has apparently not been previously studied. The administration of Disulfiram ( $3 \times 400 \mathrm{mg} /$ week) to twenty consecutive outpatients with alcoholism of $>5$ years and moderate alcoholic liver disease was supervised by a trustee, in collaboration with the family physician. QoL was measured with the Schedule for Evaluation of Individual Quality of Life (SEIQOL) [McGee HM, O'Boyle CA, Hickey A, Joyce CRB and O'Malley K. Assessing the quality of life of the individual: the SEIQOL with a healthy and a gastroenterology unit population. Psychol Med 21:749-759, 1991; O'Boyle $\mathrm{C}, \mathrm{McGee} \mathrm{H}$, Hickey A, O'Malley K and Joyce CRB. Individual quality of life in patients undergoing hip replacement. Lancet 339:1088-1091, 1992]. QoL and liver function were assessed at baseline and after 6 months. QoL was also assessed in 20 volunteers matched for sex, age, education and social status. For patients and volunteers, respectively, SEIQoL scores were $59 \pm 12(73 \pm 10)$ at baseline and $70 \pm 10(74 \pm 7)$ after six months: at baseline but not after six months, patient QoL was significantly lower than that of volunteers (ANOVA p<0.01). Patient bilirubin, GGT, ASAT, and MCV all returned to normal in this period. Supportive treatment of ambulatory alcoholics with Disulfiram thus improved the individual perception of QoL and liver function. Qol may be an important, relevant and sensitive criterion for the assessment of treatment efficacy in alcoholism. Supported by the Swiss Foundation for Research on Alcoholism, Migros Genossenschaft, and Swiss National Science Foundation. 


\section{COMPUTER-ASSISTED COGNITIVE TRAINING WITH ALCOHOLICS}

\author{
I Giinthmer. T Hevden. K telermann. II Schmidt. K Mann
}

Deparment of Psschiatry. Unitersity of Tihingen.

Osianderstr. 22. D-72076 Tühingen. Germany

During cletoxification alcoholics sulfer from a variety of regetative simptoms. An the same time theit neuropsychological functions are severely disturbed which limits the alcoholics cognitive capacity to cope successfully with various demands during treatment.

60 alcoholics. Who undenvent a standardized inpatient detoxification treatment (3 weelsi). were assigned to one of three modes of intervention ( $n=20$ for each group :

$C A C T=$ computer-assisted cognitive training of topological (nonverbal) memory. $. \backslash C C T=$ non-computer-assisted cognitive training by using selected nonverbal memory games. $R P C G=$ role plaving control group. All three groups were tested neuropsichologically before and after their specific treatment.

The results showed that both cognitive training groups, be it computer-assisted or not, improved significantly on their nonverbal memory as compared to the third (control) group, but not on other measures of general intelligence.

We thus conclude that cognitive training can improve selected neuropsychological functions in alcoholics, be it with or without the assistance of a computer.

\section{ALCOHOLISM TREATMENT WITH SEROTONERGIC ANTIDEPRESSANTS}

N.N. Ivanets

Institute on Medicobiological Problems of Addiction, Malyi Mogiltsevsky per. 3, 1219921 Moscow, Russia

Further development of pathogenetic approaches to alcoholism treatment involves clinical trials of fluvoxamine and trazodone. Data are available on the possibility of regulating catecholamine (CA) metabolism, a key biological factor in alcohol dependence, through the serotonin neurotransmission system. The goal of this work was to study the effect of fluvoxamine and trazodone as anti-craving drugs. The clinico-biochemical method was used. Fluvoxamine and trazodone were given to patients with alcohol dependence syndrome. The results obtained indicate that fluvoxamine and trazodone are highly effective as anticraving drugs. Pathological craving for alcohol is effectively arrested when manifested by depression with anxiety and irritation within the dependence syndrome structure. This concems the use of fluvoxamine and trazodone in both the withdrawal syndrome and remission (for stabilizing emotional condition and preventing a relapse). Favourable clinico-biochemical correlations have been found between deactualization of the pathological craving for alcohol and the normalization of CA metabolism. The data obtained permit us to recommend fluvoxamine and trazodone for the treatment of alcohol dependence syndrome.
AN ADDICTION LIAISON SERVICE IN NORTHERN GERMANY U John, U Hapke, H-J Rumpf, C Veltrup, M Driessen Medical University of Luebeck, Clinic of Psychiatry, Ratzeburger Allee 160, D-23538 Luebeck, Germany.

The background of the presentation is the fact that ten to twenty percent of the patients in general hospitals are to be diagnosed as alcohol dependents. The aim is to present the work and preliminary data of a liaison service for alcohol dependent in-patients in a general hospital. The work load of the service includes a screening of patients with the focus on alcoholism and a consultation for those patients diagnosed as alcohol dependents or abusers. They may take part in a three-week-motivational treatment programme in a nearby psychiatric university clinic. The purpose of this secondary preventive in-patient programme is to foster decisions about how to cope with alcohol abuse. The results of the practical experience as well as first descriptive studies show that the addiction liaison service works. Patients who took part in the three-week-programme show a higher proportion of abstainers one year after treatment than those who had just one consultation contact. The conclusion is drawn that motivational treatment units should be established in general hospitals with coworkers experienced in psychiatry.

SERVICES FOR SUBSTANCE ABUSERS IN GREECE

\section{V.P. Kontaxakis and G.N. Christodoulou}

Center for Mental Health, Athen

Department of Psychiatry, University of Athens

74 Vas. Sophias Ave, 11528 Athens, Greece

The existing facilities for substance abuse in Greece in the year 1993 are recorded with reference to the geographical distribution of the existing units (in Nomes), the agencies which are responsible for the provision of these services (public sector, local authority, church, private agencies) the character of each unit (preventive, therapeutic etc) and the type of each unit (consultation, telephone helpline, day centers, therapeutic communities etc). The majority of these services (67\%) exist in the Attica region which includes Athens. In as many as 38 Nomes no substance abuse facilities exist. The majority of units $(63 \%)$ are state-run, the local authorities run $14 \%$ of them, $11 \%$ are based on private initiative and 3\% are church-run. Most facilities are of a preventive character $(65 \%)$ and only $21 \%$ are therapeutic. Most units (57\%) function as consultation services. Family programs and schools for parents comprise $14 \%$ of the units. Therapeutic communities (8\%), Telephone helpline units (8\%) Therapeutic communities (8\%), Telephone helpline units $(8 \%)$
rehabilitation units $(5 \%)$, inpatient therapeutic units $(2.6 \%)$ day centers $(2.6 \%)$, special outpatients units (1.3\%), hostels (1.3\%) also exist. There is an obvious need for increase in the overali number of services, for more even geographical distribution of the existing facilities and for the establishment of more inpatient therapeutic units, day centers, special outpatients units in General and Psychiatric hospitals, hostels and Emergency units. 
PRESCRIBING OR NON, ADDICTIVE DRUGS TO DRUG ADDICTS : ATTITUDES OF PROFESSIONAL WORKERS, EX-USERS AND USERS J.A. Liappas, A. Kokkevi, V. Pomini, M. Malliori, C. Stefanis Athens University Medical School Department of Psychiatry, Eginition Hospital, 74 v. Sophias Ave., 11528 Athens, Greece.

This study aims at comparing the attitudes of professional workers, ex-users and users concerning free versus controlled prescribing drugs to drug addicts.

A sample of medical doctors $(n=80)$, police and probation officers $(n=85)$, ex-users $(n=84)$ and users $(n=86)$, radomly selected, were interviewed by means of structured questionnaires.

The results show that the majority of professional workers and ex-users strongly support views against free prescribing and a substantial number of users agree that : (a) restrictions will pressurise users into taking other more easily obtainable substances and (b) restrictions will increase drug-related crime although all groups believe that restrictions will motivate users to deal more positively with their addiction.

The conclusions show that there is evidence supporting the view that there is no single answer capable of addressing the issue of prescribing versus non-prescribing addictive drugs to drug addicts.
MULTICENTRE DOUBLE-BLIND CONTROLLED TRIAL IN ALCOHOLIC PATIENTS AFTER WITHDRAWAL, DESIGNED TO COMPARE THE EFFICACY OF ACAMPROSATE AND PLACEBO OVER A 1-YEAR PERIOD

\section{E. Paille LD, Guelfi}

Centre d'Alcoologie - Hôpital Fournier 54035 NANCY France

Clinique des Maladies Mentales et de l'Encéphale - Hôpital Ste Anne 75674 PARIS France

The efficacy of Acamprosate in maintaining abstinence in weaned alcoholics has been assessed versus placebo in a 1-year treatment, 6 months follow-up controlled trial.

538 patients have been included after they have met the DSM-III-R diagnostic criteria for alcohol dependence. 32 French centres specialized in alcoholism treatment participated in the trial, 3 parallel groups were considered with 2 dosages of Acamprosate : $1.3 \mathrm{~g} /$ day, $2 \mathrm{~g} /$ day, placebo (for a 1-year treatment period). All patients received placebo during the 6-months follow-up. The first evaluation was performed prior to withidrawal, with a clinical as well as a laboratory assessment. After withdrawal, patients were assessed again on Day 0 and thereafter monthly for the first 6 months, then every 2 months until the end of the follow-up period.

The data were analysed by intention to treat. At all the assessment stages, the proposition of patients who had been abstinent since the start of the trial was highest in the acamprosate high dose group and lowest in the placebo group. The time between weaning and first retum to alcohol consumption ( $153 \pm 197$ days vs $102 \pm 165$ days) and the cumulative duration of abstinence over the whole follow-up period were significantly longer in the acamprosate high dose group.

Compliance with treatment was improved significantly in the acamprosate groups. $35 \%$ of the patients remained in the trial on placebo vs $52 \%$ in the acamprosate $2 \mathrm{~g} /$ day group. Tolerability was good, only diarrhea being significantly more frequent with acamprosate. The analysis of the six additional months on placebo did not show any differences in outcome between the three groups. The hierarchy was retained, with a gradual tendency for the groups to converge.

This study confirm the pharmacological efficacy of acamprosate as an aid to maintaining abstinence in alcohol-dependent patients. 